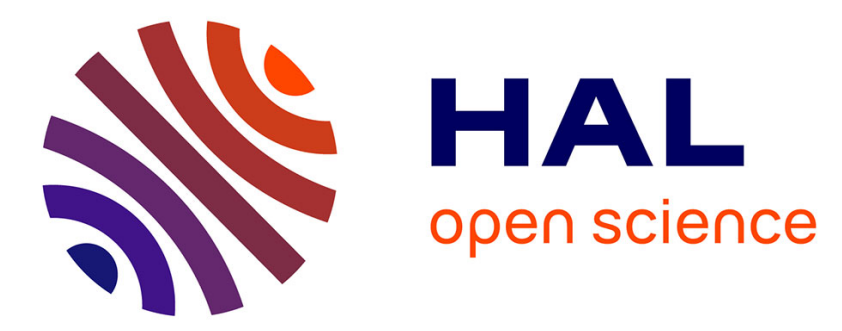

\title{
Measurement of the amount of liquid and vapour created by an electric arc on an electrode - case of $\mathrm{Ag}$ and $\mathrm{AgSnO}$ electrodes
}

\author{
Ph. Teste, R. Andlauer, T. Leblanc
}

\section{- To cite this version:}

Ph. Teste, R. Andlauer, T. Leblanc. Measurement of the amount of liquid and vapour created by an electric arc on an electrode - case of $\mathrm{Ag}$ and $\mathrm{AgSnO}$ electrodes. European Physical Journal: Applied Physics, 2011, 55 (1), 10.1051/epjap/2011100407 . hal-00719812

\section{HAL Id: hal-00719812 \\ https://hal.science/hal-00719812}

Submitted on 21 Jul 2012

HAL is a multi-disciplinary open access archive for the deposit and dissemination of scientific research documents, whether they are published or not. The documents may come from teaching and research institutions in France or abroad, or from public or private research centers.
L'archive ouverte pluridisciplinaire HAL, est destinée au dépôt et à la diffusion de documents scientifiques de niveau recherche, publiés ou non, émanant des établissements d'enseignement et de recherche français ou étrangers, des laboratoires publics ou privés. 
- Measurement of the Amount of Liquid and Vapour Created by an Electric Arc on an Electrode - Case of $\mathrm{Ag}$ and $\mathrm{AgSnO}_{2}$ electrodes

\author{
Ph. Teste ${ }^{1}$, R. Andlauer, T. Leblanc \\ Laboratoire de Génie Electrique de Paris \\ Centre National de la Recherche Scientifique (UMR 8507) - SUPELEC - University \\ of Paris 6 et Paris 11 \\ 11 rue Joliot Curie - Plateau de Moulon - 91192 Gif sur Yvette - FRANCE
}

\begin{abstract}
:
In this paper an original experimental device is presented. It allowed to obtain, for the first time, the total amount of liquid and vapour of metal created on the electrode surface by a non stationary electric arc $(600 \mathrm{~A} / 20 \mathrm{~ms})$ burning in air at atmospheric pressure. The results are presented for two different materials $\mathrm{Ag}$ and $\mathrm{AgSnO}_{2}$ and for electrode gap values in the range 1-10 millimetres. The amount of liquid and vapour created under the arc action is compared with usual erosion rate in the same experimental conditions. In the case of Ag electrodes the amount of liquid metal created on the anode may be 3 to 5 times higher than on the cathode although the usual erosion rates are more important at the cathode. For the anode, the usual erosion may represent a very low percentage $(<10 \%)$ of the total amount of metal liquid created showing then that a very small part of the liquid created during the arc is ejected. In the case of $\mathrm{AgSnO}_{2}$ electrodes the amount of liquid metal is smaller. The usual erosion and the total amount of liquid at the cathode are higher than for the anode and the usual erosion represent 10 to $50 \%$ of the amount of liquid and vapour created.
\end{abstract}

Pac’s numbers: $52.80 \mathrm{Mg}, \mathbf{5 2 . 5 0} \mathrm{Nn}, \mathbf{5 2 . 7 7} \mathrm{Fv}, \mathbf{5 2 . 7 5} \mathrm{Hn}$

Key Words: Electric arc, power balance, electrode erosion

Short title: Measurement of the amount of liquid and vapour created by an electric arc.

\footnotetext{
$\overline{{ }^{1} \text { E-mail address : teste@lgep.supelec.fr }}$
} 


\section{Introduction:}

Erosion of electrodes under the action of an electric arc is of great importance in many technical and scientific fields such as those of switching devices, plasma torches, lightning impact, and arc welding... For instance, in the case of switching devices, electrode erosion will govern a lot of characteristics of the devices: the quality of the contact resistance, the welding performances, ...

The erosion of the electrodes under the electric arc action results from various phenomena:

- the metal surface vaporization under the action of the intense heat flux.

- The micro-explosions of the electrode materials caused for instance by the existence of porosities in the electrode bulk or the metal vapour bubbles. Such phenomena may occur when hot zones appear under the electrode surface [1]

- The ejection of liquid metal droplets. Several authors [2 - 5] have been interested in the description of the metal fluxes ejected by liquid metal droplets and for instance by the angular distribution of the ejection or by the size distribution of the ejected droplets. The droplets are most of the time collected with the help of a shield placed around the arc gap [6]. There exist several models of the ejection mechanisms. In [4] it was explained that the radial ejection is due to the action of the arc pressure on the liquid metal. In [3], the axial ejection of liquid metal is caused by the stop of ionic forces at the end of the arc. In [7] the authors have considered the action of other forces: during the arc, the melted metal may be submitted to intense forces (Lorentz forces or forces resulting from a superficial strain gradient). These forces may have enough time to generate motions in the melted pool and then to cause metal droplet ejections.

It should be emphasized that with these methods only the amount of ejected metal may be measured. An unknown part of liquid metal may remain on the electrode surface and solidify after the end of the arc. 
The aim of this study was the experimental determination of the amount of liquid and vapour of electrode metal created by a non stationary electric arc burning at atmospheric pressure in air. This determination presents a double interest:

- Such an experiment may become an interesting characterization device for electrode materials.

- The knowledge of the amount of liquid and vapour created may be useful for an indirect determination of the power balance (power and surface power density) at the electrode surface of an electrode submitted to an electric arc.

The paper is organized as follows:

- In the first part, the experimental device and the experimental method are described.

- In the second part the experimental results concerning the total amount of liquid and vapour created on the electrodes are presented for $\mathrm{Ag}$ and $\mathrm{AgSnO}_{2}$ cathodes and anodes for different values of the electrode gap (denoted d) in the range 1 - 10 millimetres. Comparisons are also proposed with usual erosion rates obtained in similar experimental conditions for the same range of electrode gap values.

- The last part is devoted to the result discussion.

\section{Description of the Experimental Device and of the Principle of the Experiment.}

\subsection{Description of the experimental device}

The experimental device may be divided in two parts:

- An electrical system allowing to generate arc current pulses of constant intensity (200 A $<I_{a r c}<800 \mathrm{~A}$ ) and constant electrode gap $d$ until $d=10 \mathrm{~mm}$. The arc duration $d t$ is controlled and included between 5 and 30 ms. This device has already been described in detail in [8]. The arc ignition is realized with the help of an HV pulse (30-40 kV). 
- A mechanical system described in figure 1. Two electrodes (1) are fixed a distance $d$ apart in a cylindrical vessel (2) along a radial direction. This vessel is made with a metal cylinder and possesses a vertical axis (3) fixed at its bottom and electrically insulated from it by means of a glass epoxy piece (4). Ball-bearings (5) allow this vessel to be rotated at a controllable angular frequency $\omega$ up to $300 \mathrm{rad} / \mathrm{s}$. One of the two electrodes is fixed on the shaft, the other one is fixed on the cylinder inner wall and the arc current is provided to the electrodes through liquid $\mathrm{Hg}$ sliding electrical contacts (6). The aerodynamic flow conditions in the rotating cylinder are such that there is no velocity of the air relatively to the electrodes.

\subsection{Principle of the experiment and experimental conditions}

The electric arcs have been realized for various $\omega$ values. The liquid metal created under the arc action on the inner electrode surface is then submitted to the radial acceleration $\Omega=\mathrm{R} \omega^{2}$ ( $\mathrm{R}$ is the distance between the "inner" electrode surface and the rotation axis). The aim of the experiment is to reach a sufficient acceleration in order to eject all the liquid metal created during the arc.

The electrode materials are silver and silver tin oxide, denoted respectively Ag and $\mathrm{AgSnO}_{2}$. The mass losses have been measured by weighting the electrode before and after the arcs with a micro scales (resolution $20 \mu \mathrm{g}$ ). Only the mass loss of the inner electrode from which the liquid metal may be easily ejected was measured. Moreover, according the electric connection, the inner electrode may be anode or cathode. The ambient gas was composed by "dry" nitrogen (80\%) and oxygen (20\%). Its pressure was controlled and equal to one atmosphere. All the erosion tests have been realized with 8 millimetres diameter electrodes. In all the cases, the electrodes were polished with the help of a "spray diamond" which gives an average roughness of $3 \mu \mathrm{m}$. After, they were cleaned with the help of alcohol.

In this study the electric arc characteristics are the following:

- the arc current $\left(I_{\text {arc }}\right)$ is equal to $600 \mathrm{~A}$.

- the arc duration $(d t)$ is equal to $20 \mathrm{~ms}$.

- The electrode gap $d$ is constant during the arc and is in the range 1-10 mm. The precision for the d adjusting is about $0.1 \mathrm{~mm}$. 
- Various values of $\omega$ (up to $300 \mathrm{rad} / \mathrm{s}$ which corresponds to a velocity of 10 $\mathrm{m} / \mathrm{s}$ ) were used.

Before presenting the results it is important to note that:

- the results concerning the electrode erosion presented here after have been obtained for a sufficiently important number of arcs in order to have an erosion rate independent on the arc numbers. For $\omega=0 \mathrm{rad} / \mathrm{s}$ and according the electrode material, this arc number is about one or two hundred [9]. For $\omega_{\max }=$ $300 \mathrm{rad} / \mathrm{s}$ the number of arcs necessary for having the erosion rate independent of the arc number is smaller. For $I_{\text {arc }}=600 \mathrm{~A}$ it was observed that about 10 to 20 arcs were sufficient in order to have a mass loss erosion independent from the number of arcs. A proposition of explanation is given in 3.1.

- each measure was realized on about ten electrodes.

In the case of static arcs, it has been noted in [10] that, for $I_{\text {arc }}$ in the range of some hundreds of amperes, for $\mathrm{AgSnO}_{2}$ contacts, the erosion rate obtained by measurement of the mass loss is constant even for the first arcs.

It is also important to try to answer the following question: does the rotation perturb strongly the electric arc?

For that, the influence of the rotation on the arc voltage was first studied. In figure 2, the evolution versus the electrode gap of the mean arc voltage (during the arc duration) in the case of static electrodes [9] is recalled for the same experimental conditions (600 A, $20 \mathrm{~ms}$, covering gas). The mean arc voltage varies linearly versus the electrode gap and may be written under the following form: $U_{a r c}=V_{0}+E \times d$ Where:

- $\quad d$ is the electrode gap

- $E$ is the mean (spatial) electric field in the arc column 
$V_{0}$ is the sum of the anodic voltage fall $\left(V_{A}\right)$ and the cathodic one $\left(V_{C}\right)$. It is determined by extrapolating for $d \rightarrow 0 \mathrm{~mm}$.

$E$ and $V_{0}$ values obtained in [9] are recalled in table I for the two materials. It was observed that the mean spatial electric field and the sum of the anodic and cathodic voltage drop for Ag electrodes are greater than for $\mathrm{AgSnO}_{2}$.

For $\omega=\omega_{\max }$ it was observed that the rotation had practically no influence on the mean arc voltage value. The measurement of the arc voltage versus time was made with a 12 bits oscilloscope (with a resolution of $5 \mathrm{mV}$ ). The mean arc voltage in time was calculated for each arc and the average $U_{\text {arc }}(d)$ value was then calculated on twenty arcs. It was observed that the difference the most important between both $U_{\text {arc }}(d)$ curves is smaller than $1 \mathrm{~V}$. We have then obtained a curve quasi-similar to that of figure 2. That means that:

- the macroscopic property of the arc column (the mean electric field) is not changed by the rotation.

- the sum of the anodic and cathodic voltage falls which characterized physical phenomena occurring very near the electrode surfaces is not changed.

These two points constitute an argument allowing to think that the rotation does not perturb strongly neither the arc column nor the cathodic or anodic zone structures.

In figure 3 an example of the time evolution of the arc voltage in two cases ( $\omega$ $=0$ and $\omega=\omega_{\max }=300 \mathrm{rad} / \mathrm{s}$ ) is given for Ag electrodes and an electrode gap equal to $7 \mathrm{~mm}$. In the two cases the average arc voltages are very near (51.2 and $51.9 \mathrm{~V})$. In the static case standard deviation is equal to $4 \mathrm{~V}$ in the rotating case $\left(\omega=\omega_{\max }\right)$ the standard deviation is equal to $6 \mathrm{~V}$. Moreover, the automatic measurement of the arc duration has allowed to observe that no self shrinking occurred during the arc in the two erosion modes. It is important to note that even the difference between the two curves may reach $10 \mathrm{~V}$, this is not due to the rotation but to the intrinsic arc instability. Such a difference may also be observed between similar arcs at $\omega=0 \mathrm{rad} / \mathrm{s}$. 
It is also interesting to compare the forces exerted on the various particles (electrons, ions...) in the plasma to the centrifugal forces exerted by our device. A study of the intensity of forces exerted was proposed in [11]. These forces are several orders of magnitude greater than the centrifugal forces exerted here. That contributes also to justify the fact that the plasma is not strongly perturbed by the rotation.

Furthermore, in the cases of a non stationary arc burning in air, an important ejection of liquid metal may occur. For instance, we present in figure 4 a photography of an electrode surface in Ag submitted to an electric arc (600 A) in air. The electrode surface has been observed with the help of an high speed camera (6000 fr/s). The surface was lightened during the arc with the help of a DC laser and the surface observed with the help of an interference filter centred on the laser wavelength. In these conditions the observation of the surface is made possible despite the electric arc presence. Numerous liquid metal droplets, ejected during the arc duration are observed and interact with the arc.

With all these elements, the assumptions were made that the rotation does not perturb strongly the electric arc and more particularly the anode or cathode zones near the surfaces.

\section{Experimental Results}

In this part, results concerning the influence of $\omega$ on the mass loss are presented.

\subsection{Influence of $\omega$ on the mass losses}

In figure 5 , the mass loss (in $\mathrm{mg} / \mathrm{arc}$ ) has been plotted versus $\Omega$ for an $\mathrm{Ag}$ anode for $I_{\text {arc }}=600 \mathrm{~A}$. The arc duration $d t$ is equal to $20 \mathrm{~ms}$ and the electrode gap is equal to 8 millimetres.

A plateau was observed when $\Omega$ increases which showed that for $\omega=\omega_{\max }=$ $300 \mathrm{rad} / \mathrm{s}$ the measured mass loss corresponds to the total amount of vapour plus liquid metal formed by the arc action on the electrode surface. Similar observations have been made for other $d$ values and for $\mathrm{AgSnO}_{2}$ electrodes. 
Furthermore an observation of the "inner" electrode surfaces after the tests shows that there is no more liquid metal tracks on the surface. All the liquid metal has been ejected.

For $\omega=\omega_{\max }$ the erosion rate becomes independent on the arc number for a small number of arcs.

The total amount of liquid and vapour is directly connected to the power balance at the electrode surface which should be reproducible, whereas the static erosion rate depends also on liquid motion in the melted zone and on droplet ejection phenomena.

Hereafter, the two erosion modes $(\omega=0)$ and $\left(\omega=\omega_{\max }\right)$ are compared:

- the first mode is usual, it consists in weighing the mass losses in the case of motion less electrodes $(\omega=0)$. It is called in this work "static erosion mode". The results have already been presented in [9] and are recalled here for the comparison.

- The second erosion mode consists in measuring the mass losses obtained for $\omega$ $=\omega_{\max }$. These mass losses were called: the total amount of liquid and vapour formed by the arc on the electrode surface, and denoted "TALV".

3.2 Influence of electrode gap - Comparison between the static erosion [9] and the "TALV" values

In figures 6 to 9 we present the TALV values obtained here and we recall the mass losses (in $\mathrm{mg} / \mathrm{arc}$ or in $\mathrm{mg} / \mathrm{C}$ ) versus $d$ measured in the case of static erosion for:

- $\quad$ Ag cathodes in figure 6 .

- $\quad$ Ag anodes in figure 7.

- $\mathrm{AgSnO}_{2}$ anodes in figure 8.

- $\mathrm{AgSnO}_{2}$ cathodes in figure 9. 
The experimental dispersion of the measurements is presented. In the figures the minimal and maximal values measured as well in the case of the static erosion or in the case of the TALV values were plotted.

\section{Comments:}

Case of Ag cathodes (figure 6):

For Ag cathodes the static erosion rate and the TALV value vary approximately similarly versus $d$. In the two cases a decrease of the mass losses is observed. Furthermore, for the two erosion modes the mass losses are quasiindependent on $d$ as soon as $d$ is greater than $8 \mathrm{~mm}$.

\section{Case of Ag anodes (figure 7):}

For Ag anodes the variations of the mass losses are opposed: the static erosion rate decreases versus $d$, whereas the TALV value increases. However, in the two cases the mass losses are quasi-independent on the electrode gap value as soon as it is greater than $7 \mathrm{~mm}$.

\section{Case of $\mathrm{AgSnO}_{2}$ electrodes (figures 8 and 9):}

For $\mathrm{AgSnO}_{2}$ electrodes, the static erosion rate and the TALV value vary qualitatively approximately similarly versus $d$ until $d$ is equal to $7 \mathrm{~mm}$. However, for higher $d$ values, the TALV increases strongly with $d$ whereas the static erosion rate remains constant.

In figure 10 the ratio between the TALV value and the static erosion rate versus the electrode gap for the two materials and polarities is presented:

- This ratio may reach very high values: more than 50 in the case for Ag anodes: that means that a very small proportion of the liquid created has been ejected under the sole arc action.

- Most of the cases this ratio is greater for the anodes than for the cathodes.

- For an equivalent electrode polarity, this ratio is smaller for $\mathrm{AgSnO}_{2}$ than for Ag. That may be due to the fact that the thermal conductivity of $\mathrm{AgSnO}_{2}$ is 
smaller than the one of Ag. In these conditions, a more important amount of vapour is created on $\mathrm{AgSnO}_{2}$ electrodes which limits the liquid metal formation.

In figures 11a and 11b the ratio between the anode mass loss and the cathode mass loss for the two erosion modes are plotted for $\mathrm{Ag}$ and $\mathrm{AgSnO}_{2}$ respectively. For the two materials, although the usual cathode erosion is more important than for the anode, the amount of liquid created on the anode is more important.

\section{Discussion}

- Various explanations concerning the variations of the static erosion rates versus the electrode gap have already been proposed in [9] and [16]. In these papers the use of a high speed camera allowed to observe the interactions between the arc and the electrodes. In tables II and III a summary of the observations for the two electrodes materials and for different polarities is proposed. However, in the case of the TALV value measurement, it was not possible to observe these interactions because of the electrode motion.

Thanks to these observations several explanations may be brought:

- The joint decrease (with $d$ ) of the usual erosion rate and of the TALV value for Ag cathodes may correlated with the decrease of the plasma/surface interactions and with a high mobility of the cathode arc root for important $d$ values. For small $d$ values, important interactions between the plasma jet generated at the anode have been observed which may contribute to an increase of the erosion rate [8], [9].

- The decrease of the anode static erosion for Ag (by a factor 20) may be linked to the weak plasma/surface interactions when the electrode gap increases and to a change of discharge mode [12-14]. 
- The increase with $d$ of the TALV value for $\mathrm{AgSnO}_{2}$ (for cathode and anode) may be linked to the decrease of the arc root mobility when the electrode gap increases. The resulting motionless heating of the surface generates then an important amount of liquid.

- The TALV value is strongly linked to the characteristics of the power balance (power and surface power density brought by the arc) at the electrode surfaces. It is also linked to the behaviour (mobility or motionlessness) of the arc root on the electrode surfaces. The static erosion rate does not give an image of the power balance because it depends on other parameters such as:

- the forces exerted on the melted pool which may cause metal droplet ejections. These forces depend strongly on the structure of the arc root but also on the material properties.

- the material viscosity which governs the motion of the liquid metal in the melted pool.

Then, the fact that for Ag electrodes the TALV value is quasi-independent on $d$ as soon as it is greater than $8 \mathrm{~mm}$ means that for these two materials the power brought to the electrodes becomes independent on the electrode gap when $d$ increases.

- For Ag and $\mathrm{AgSnO}_{2}$ anodes the usual erosion rate is lower than the one for cathodes whereas the TALV value is more important for anodes than for cathodes. That indicates that:

o The power and the surface power density at the anode generate an important amount of liquid metal and are different at the cathode.

o However, the forces exerted by the electric arc on the liquid metal, which contributes to liquid ejection, are weaker at the anode surface. Among these forces, the most important [7], [15] are the Laplace and Marangoni ones (due to the existence of an important surface temperature gradient). Then, this result may indicate that for instance the 
current density at the anode arc root, which appears in the Laplace force expression, is smaller than on the cathode.

\section{Conclusion and perspective}

For the first time, an experimental device allowing to determine the total amount of liquid metal and vapor created by an electric arc on the electrode surfaces was presented. Results have been obtained for two different usual contact materials ( $\mathrm{Ag}$ and $\mathrm{AgSnO}_{2}$ ) and for different electrode gaps. The amount of liquid created by the arc was compared with usual erosion rates obtained in the same conditions and already presented in a previous paper [9].

The main results may be summarized as follows:

- The total amount of liquid and vapor created by the arc as well as the usual erosion rate depend strongly on the electrode gap.

- According the material and the electrode polarity a great difference between the usual erosion rate and the total amount of liquid and vapor created may exist. The ratio between the two erosion modes may reach some tenths in the case of $\mathrm{Ag}$ anodes and is about 4 in the case of $\mathrm{Ag}$ cathodes. Concerning $\mathrm{AgSnO}_{2}$ this ratio remains weaker.

- For Ag, the amount of liquid metal created is more important at the anode than at the cathode whereas the anode usual erosion is smaller than the cathode one. That may be attributed to differences either in the power balance characteristics or in the arc behavior.

- Observations realized with the help of a high speed cinematography allowed to explain some of the measurements. In the case of Ag cathodes the results may be explained by a change of mobility of the electric arc on the electrodes. In the case of Ag anodes the results have been explained by a change of discharge mode.

In a future work the case of copper electrodes will be studied and for this material an assessment of the power balance at the electrode surface (determination of the power 
and of the surface power density brought by the arc to the electrode) will be proposed thanks to the measurement of the TALV value and the use of a simple modeling of the thermal phenomena occurring in an electrode submitted to an electric arc. 


\section{Reference List}

[1] Z.J. He, R. Haug, J. Phys. D: Appl. Phys. , 26 , pp. 1-12, 1997

[2] D.T. Tuma, C.L. Chen, and D.K. Davies, J. Appl. Phys. 49, p. 3821 (1978).

[3] E. W. Gray and J. R. Pharney, J. Appl. Phys. 45, 667 (1974).

[4] E. Hantzsche in Proceedings of the $7^{\text {th }}$ Int. Symposium on Discharges and Electrical Insulation in Vacuum, 1976, p. 324

[5] J.E. Daalder: J. of Phys. D : Appl. Phys, 9, pp. 2379-2395 (1976)

[6] M.B. Schulman, P.G. Slade, L.D. Loud and W. Li in Proceedings of the $44^{\text {th }} \mathrm{Holm}$ Conference on Electrical Contacts, Arlington, 1998, p307

[7] J.-P. Chabrerie, L. Boyer in Proceedings of the $13^{\text {th }}$ Int. Conference Electrical Contact Phenomena, Lausanne, 1986, P.96-100

[8] Ph. Teste, R. Andlauer, T.Leblanc, J.-P. Chabrerie: Plasma Sources Science and Technology, 10, ${ }^{\circ} 1$, pp.10-16, (2001)

[9] A.M. Gouega, Ph. Teste, R. Andlauer, T. Leblanc and J.-P Chabrerie: Eur. Phys. J. Appl. Phys., 11, pp. 111-122, (2000)

[10] P. Colombo, M. Bigliati, C. Lonzar in Proceedings of the Society of Automobile Engineers World Congress, Detroit, 2002, USA.

[11] J. Haidar, PhD Thesis, University of Paris 6, (1989)

[12] N A Sanders, K Etemadi, K C Hsu and E. Pfender, J. Appl. Phys., 53, pp. 413645, (1982)

[13] N A Sanders and E. Pfender, J. Appl. Phys. 55, pp. 714-22, (1984)

[14] T. Amakawa, J. Jenistaz, J. Heberlein and E. Pfender, J. Phys. D: Appl. Phys. 31 pp. 2826-2834, (1998)

[15] J. Devautour, PhD Thesis, University of Paris 6, 1992

[16] A. M. Gouega, PhD Thesis, University of Paris 11, 1995 


\section{Figure Captions}

Figure 1: mechanical scheme of the device:

1) copper electrodes - 2) cylindrical vessel - 3) vertical shaft - 4) glass epoxy piece - 5) Ball bearings - 6) Liquid metal (sliding contact) - 7) Base piece (epoxy) - 8) Electric arc - 9) Current leads

Figure 2: mean arc voltage versus the electrode gap for I $=600 \mathrm{~A}$ and for different electrode materials ( $\mathrm{Ag}$ and $\mathrm{AgSnO}_{2}$ ).

Figure 3: two examples of the time evolution of the arc voltage in the two erosion modes $\left(\omega=0\right.$ or $\left.\omega=\omega_{\max }\right)$ - Ag electrodes $-\mathrm{d}=7 \mathrm{~mm}$.

Figure 4: photography of an electrode surface in Ag submitted to an electric arc (600 A) in air - Important liquid metal droplet ejection.

Figure 5: mass loss in mg per arc versus the acceleration for Ag anodes

Figure 6: static erosion rate [9] and "talv" value versus $d$, in mg/arc for Ag anode.

Figure 7 static erosion rate [9] and "talv" value versus $d$, in mg/arc for Ag cathode.

Figure 8: static erosion rate [9] and "talv" value versus $d$, in mg/arc for $\mathrm{AgSnO}_{2}$ anode.

Figure 9: static erosion rate [9] and "talv" value versus $d$, in mg/arc for $\mathrm{AgSnO}_{2}$ cathode.

Figure 10: ratio between static and "talv" value versus electrode gap for Ag and $\mathrm{AgSnO}_{2}$ electrodes and for cathodes and anodes.

Figures 11(a) and 11(b):

(a): ratio between the anode mass loss and the cathode mass loss for the two erosion modes (usual erosion and talv value - Case of Ag electrodes

(b): ratio between the anode mass loss and the cathode mass loss for the two erosion modes (usual erosion and talv value - Case of $\mathrm{AgSnO}_{2}$ electrodes 
Table I: $\mathrm{E}$ and $\mathrm{V}_{0}$ values obtained in [9] for the two materials.

\begin{tabular}{|c|c|c|}
\hline Electrode materials & $\begin{array}{c}\text { Mean electric field } \\
\mathrm{E}(\mathrm{V} / \mathrm{mm})\end{array}$ & $\mathrm{V}_{0}=\mathrm{V}_{\mathrm{A}}+\mathrm{V}_{\mathrm{C}}$ \\
\hline $\mathrm{Ag}$ & 4.22 & $20.8 \mathrm{~V}$ \\
\hline $\mathrm{AgSnO}_{2}$ & 3.4 & $14.4 \mathrm{~V}$ \\
\hline
\end{tabular}

Table II: Summary of the observations in the case of the cathode arc roots.

\begin{tabular}{|c|c|c|}
\hline & Small d values $(\approx 3 \mathrm{~mm})$ & $\begin{array}{l}\text { Important d values }(\approx 10 \\
\mathrm{mm})\end{array}$ \\
\hline Ag Cathode & $\begin{array}{l}\text { Motionless arc root - } \\
\text { Important plasma } \\
\text { jet/surface interactions } \\
\text { «Cathode jet dominated } \\
\text { mode » }\end{array}$ & $\begin{array}{c}\text { Mobile arc root - - Weak } \\
\text { plasma jet/surface } \\
\text { interactions } \\
\text { « Anode jet dominated } \\
\text { mode » }\end{array}$ \\
\hline $\mathrm{AgSnO}_{2}$ Cathode & $\begin{array}{c}\text { Mobile arc root - - } \\
\text { Important plasma } \\
\text { jet/surface interactions }\end{array}$ & $\begin{array}{c}\text { Motionless arc root - Weak } \\
\text { plasma jet/surface } \\
\text { interactions }\end{array}$ \\
\hline
\end{tabular}

Table III: Summary of the observations in the case of the anode arc roots.

\begin{tabular}{|c|c|c|}
\hline & Small d values $(\approx 3 \mathrm{~mm})$ & $\begin{array}{l}\text { Important } \mathrm{d} \text { values }(\approx 10 \\
\mathrm{mm})\end{array}$ \\
\hline Ag Anode & $\begin{array}{l}\text { Motionless arc root - } \\
\text { Important plasma } \\
\text { jet/surface interactions } \\
\text { « Cathode jet dominated } \\
\text { mode » }\end{array}$ & $\begin{array}{l}\text { Motionless - Weak plasma } \\
\text { jet/surface interactions } \\
\text { « Anode jet dominated } \\
\text { mode » }\end{array}$ \\
\hline $\mathrm{AgSnO}_{2}$ Anode & \begin{tabular}{l} 
Mobile arc root -- \\
Important \\
\multicolumn{2}{c}{ plasma } \\
jet/surface interactions
\end{tabular} & $\begin{array}{l}\text { Motionless arc root - Weak } \\
\text { plasma jet/surface } \\
\text { interactions }\end{array}$ \\
\hline
\end{tabular}




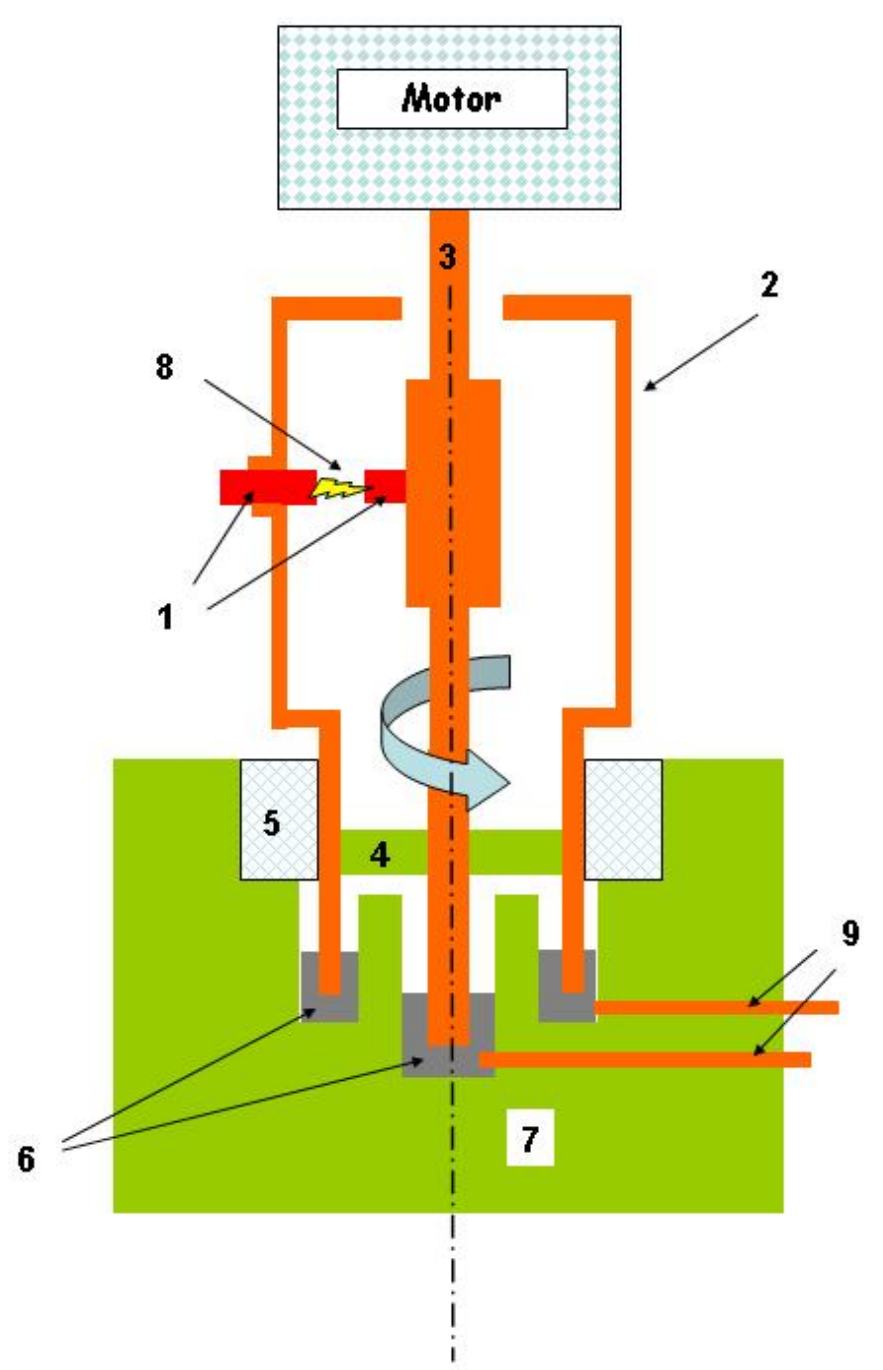

Fig 1 


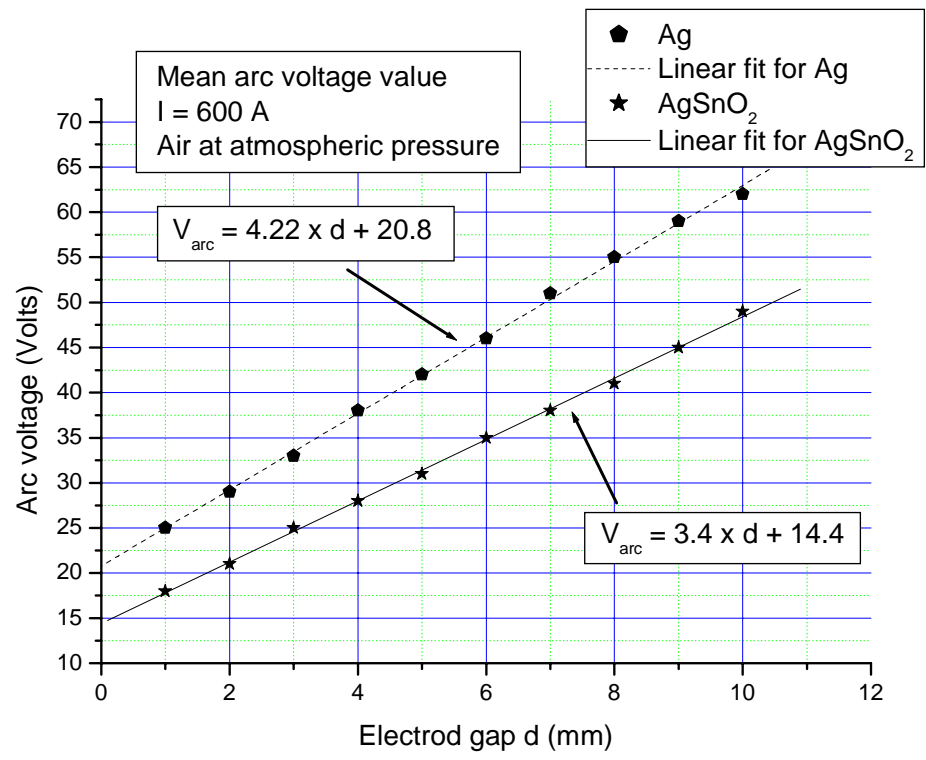

Fig. 2

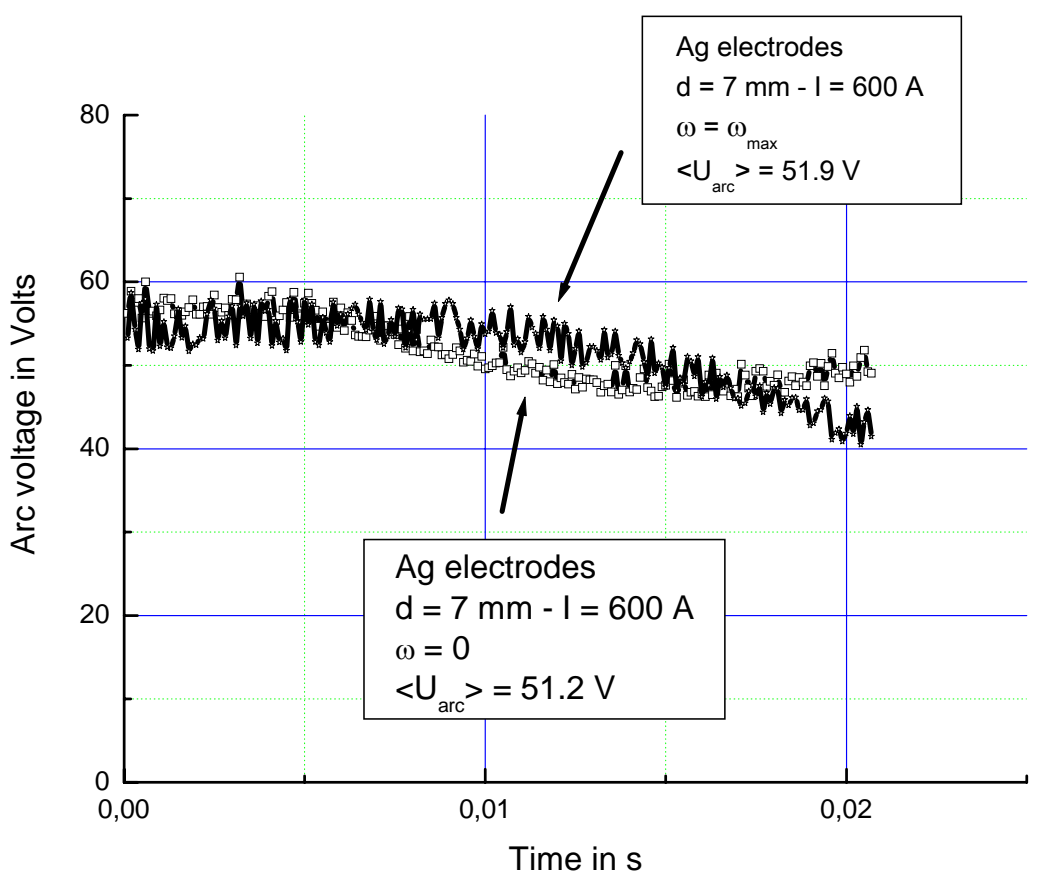

Fig. 3 


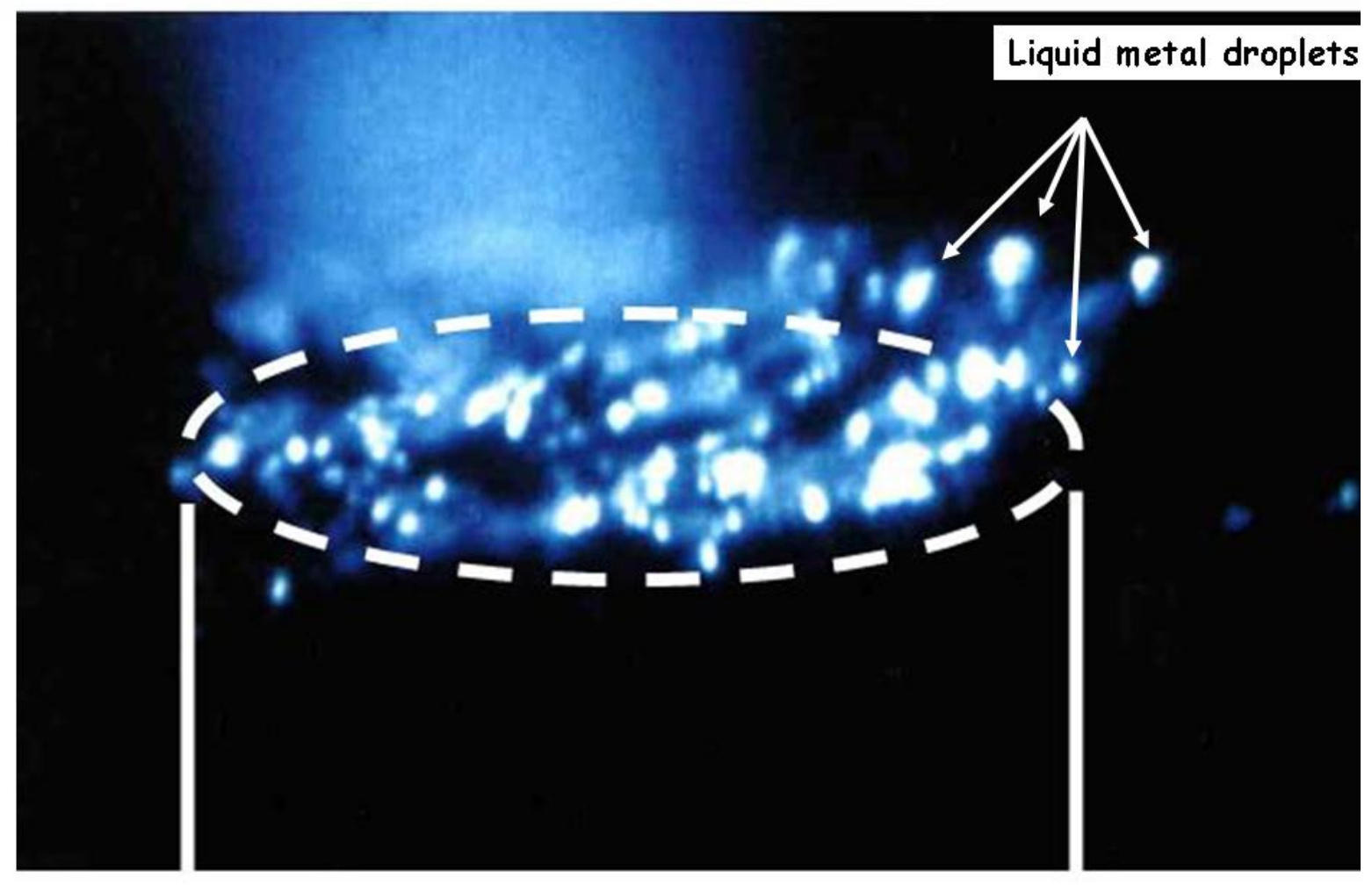

Fig. 4 


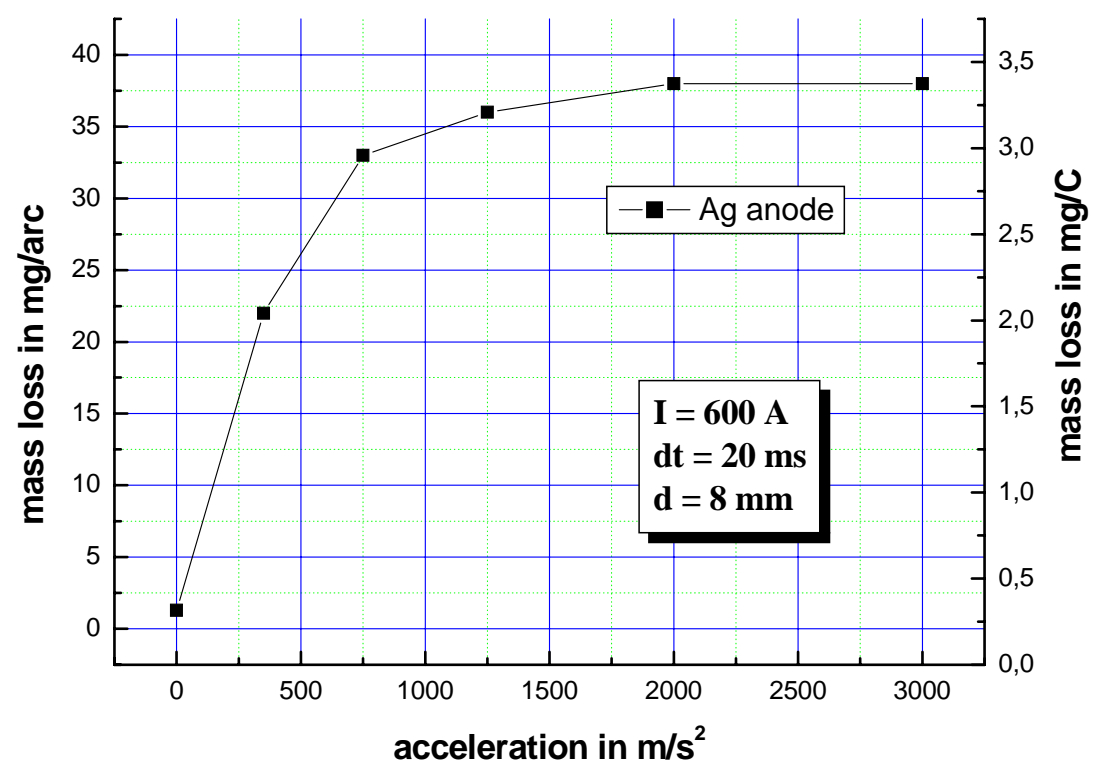

Fig. 5

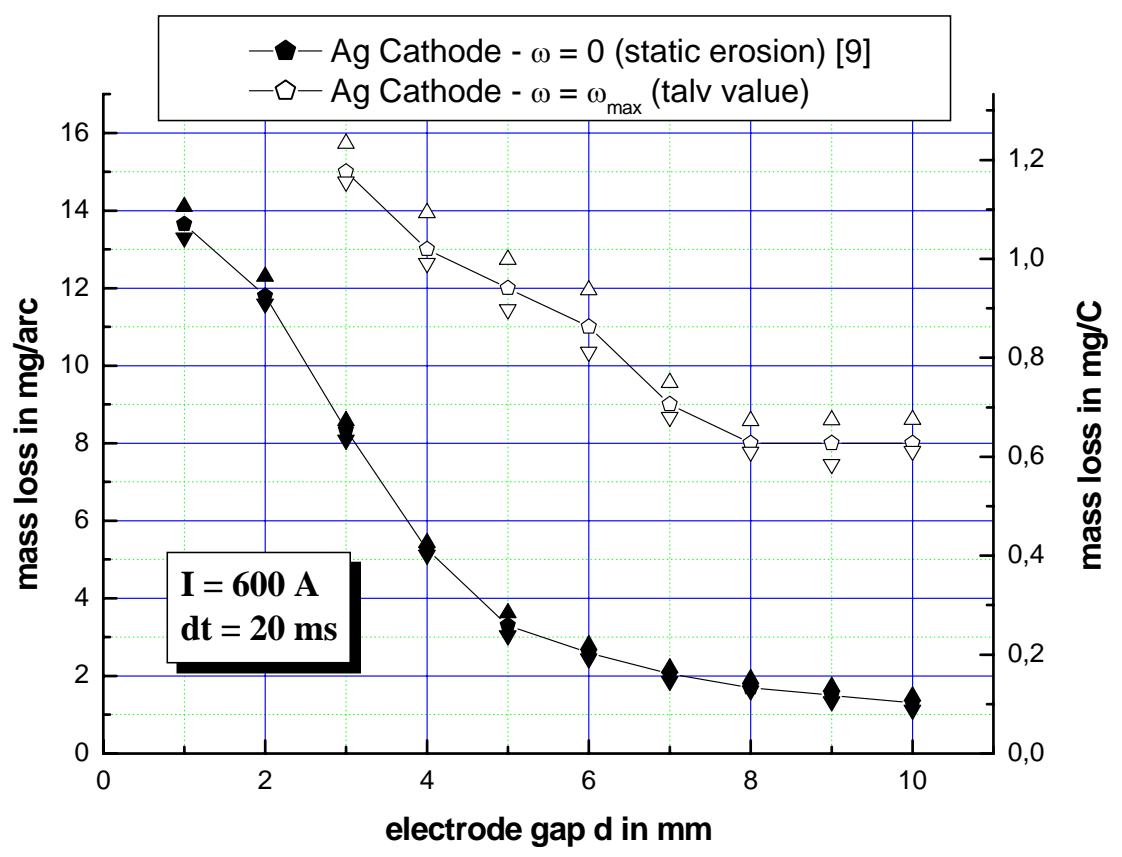

Fig. 6 


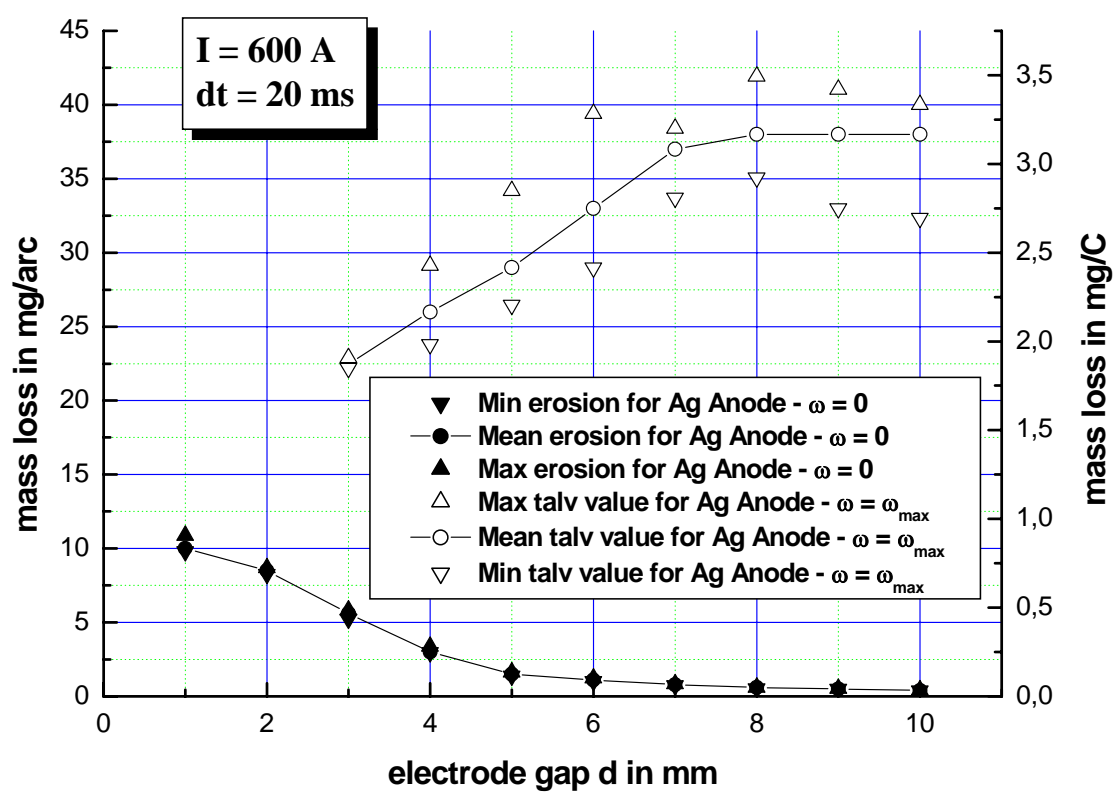

Fig. 7

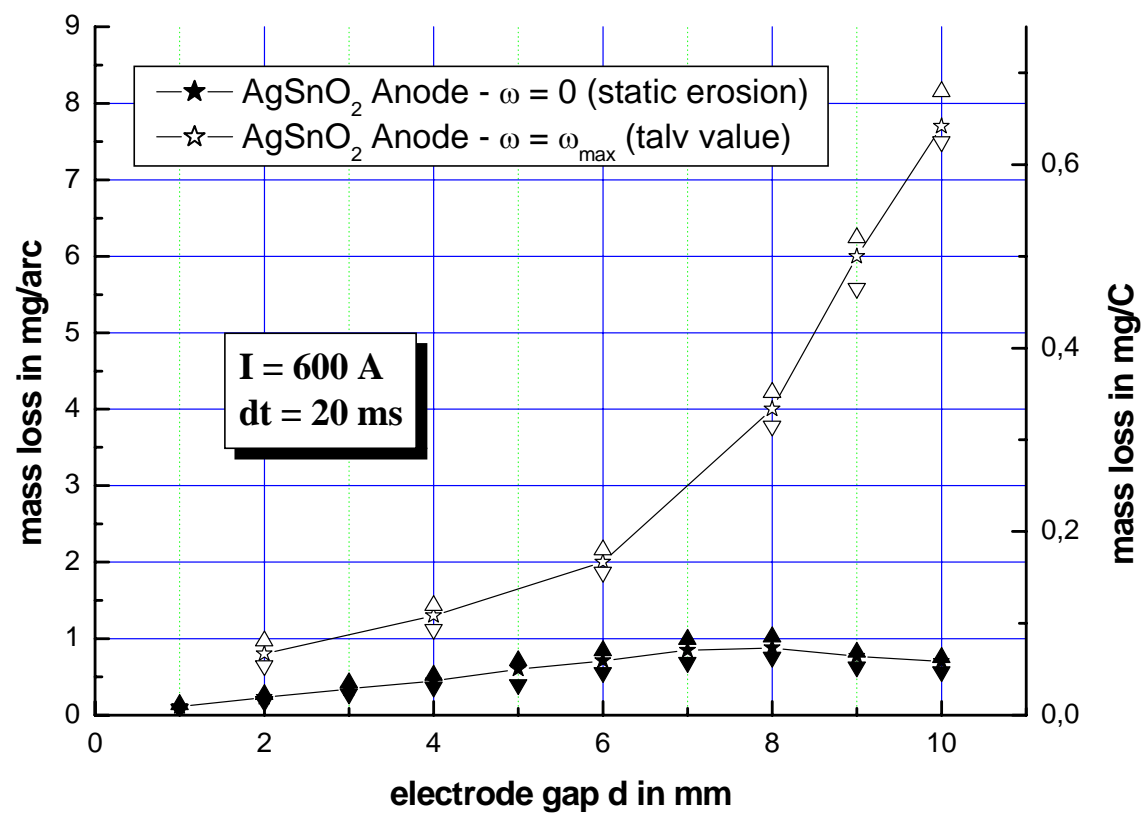

Fig. 8 


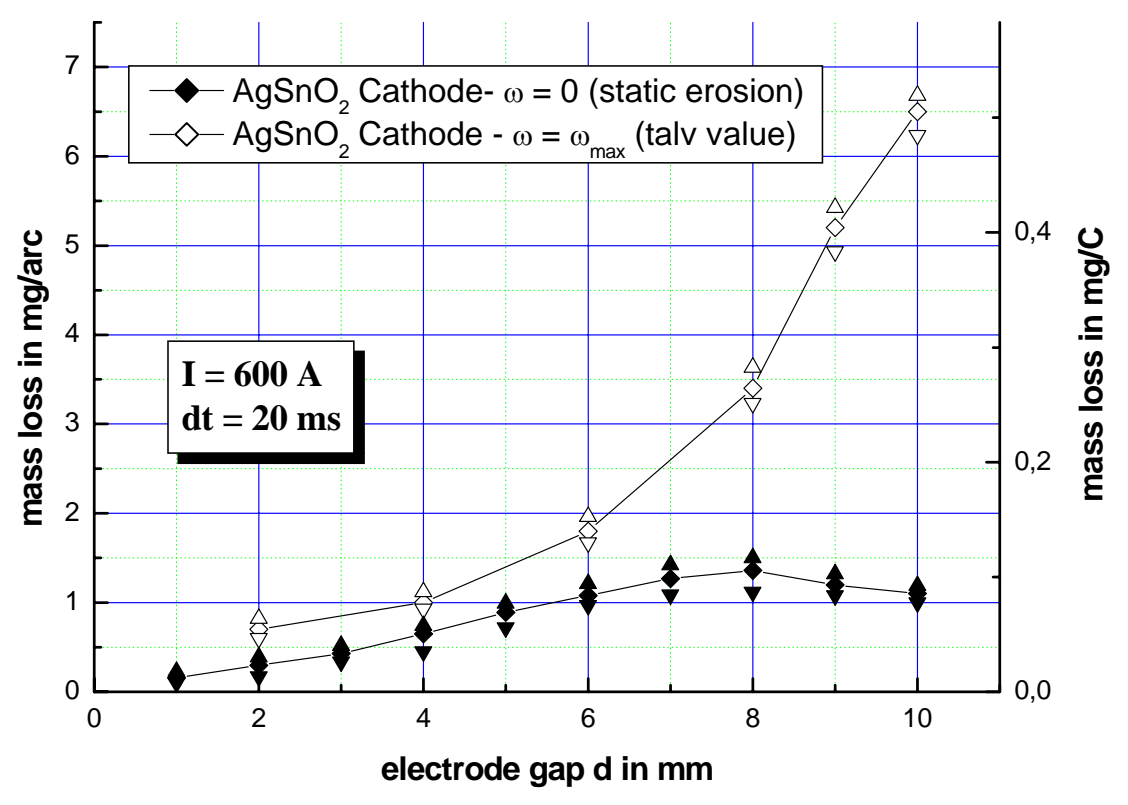

Fig. 9

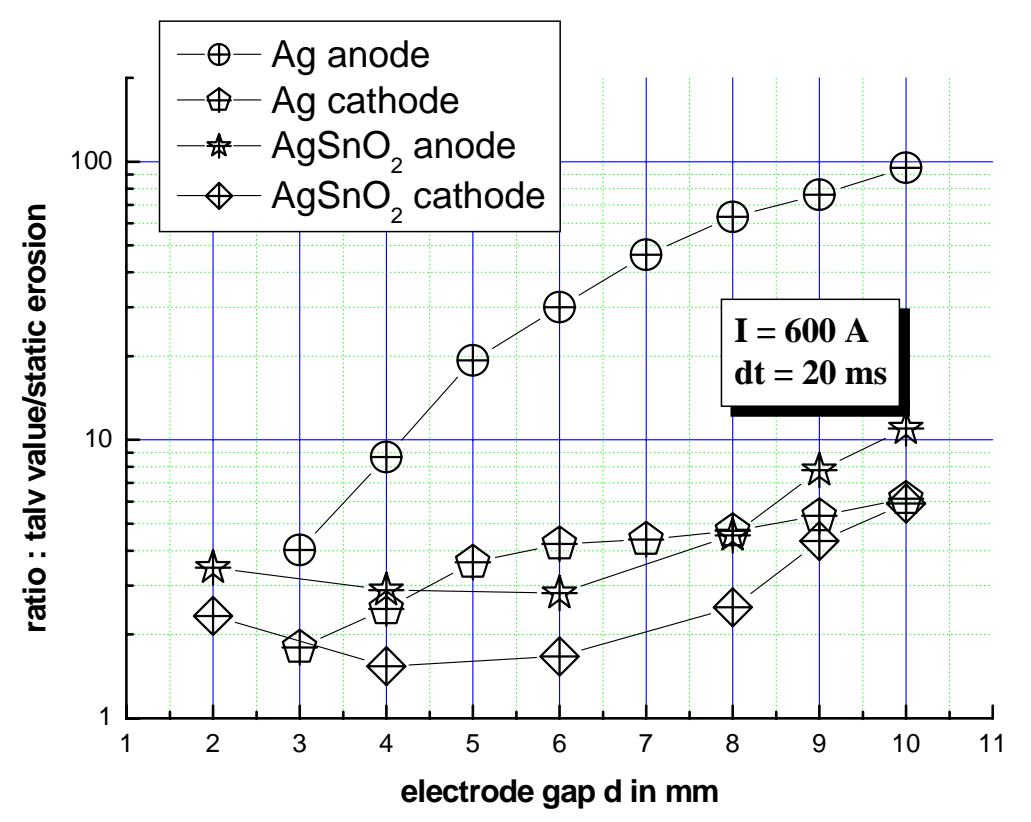

Fig. 10 


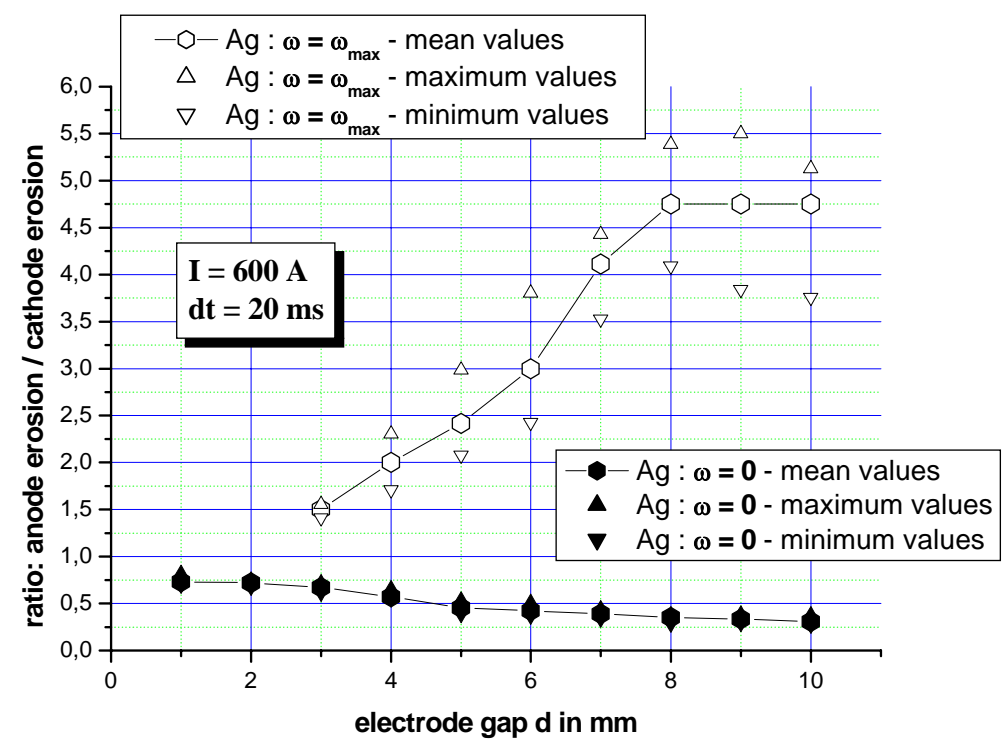

Fig. 11(a)

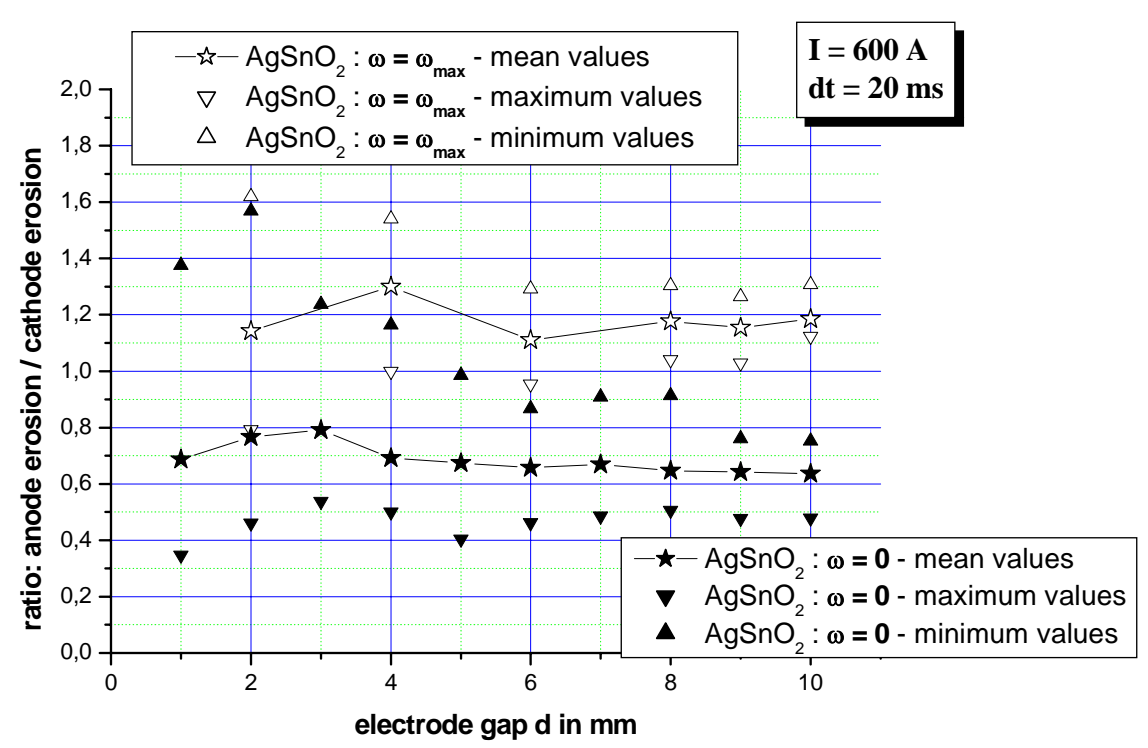

Fig. 11(b) 